\title{
Measurement of Cardiac Output in
}

\section{Man with a Nonrecirculating Indicator}

\author{
Stephen M. Wittenberg, Francis J. Klocke, David G. Greene, Ivan L. Bunnell, \\ Herman L. Falsetti, and Joseph A. ZizzI \\ From the Department of Medicine, State University of New York at Buffalo, \\ Buffalo, New York 14215
}

A B S T R A C T The present investigation was undertaken to evaluate the utility of constant-rate injection of a nonrecirculating indicator $\left(\mathrm{H}_{2}\right)$ for the measurement of cardiac output in man. 42 patients were studied during cardiac catheterization and 8 during acute complications of arteriosclerotic heart disease, including acute myocardial infarction. Pulmonary (or systemic) arterial $\mathrm{H}_{2}$ concentration was measured chromatographically from $2.0 \mathrm{ml}$ blood samples drawn during constant-rate injection of dissolved $\mathrm{H}_{2}$ into the systemic venous circulation (or left heart). The chromatograph was a thermal conductivity unit housed in a constant-temperature water bath to achieve an improved signal-to-noise ratio. Intrapulmonary $\mathrm{H}_{2}$ elimination from mixed venous blood was measured directly in 14 patients and averaged $98 \pm 1.5 \%$ (SD). Reproducibility of output measurements was evaluated using triplicate determinations obtained over $45-60 \mathrm{sec}$ in 25 consecutive patients. Coefficients of variation $(\mathrm{sD} /$ Mean $\times 100)$ averaged $3.4 \pm 2.0 \%$, making it possible to evaluate relatively small changes in measured output with conventional statistical tests. Individual measurements could be repeated at 10-15 sec intervals. Comparisons of $\mathrm{H}_{2}$ and direct Fick measurements were made in 14 patients; $\mathrm{H}_{\mathbf{8}}$ outputs averaged $106 \pm 4 \%$ (SEM) of Fick outputs $(P>$ 0.1 ). Comparisons of $\mathrm{H}_{2}$ and dye dilution measurements were performed in an additional 24 patients. Seven had angiographically-negligible valvular regurgitation and dye outputs averaged $106 \pm 3 \%$ of $\mathrm{H}_{2}$ outputs $(P>0.1) .17$ had moderate-to-severe regurigation and dye outputs averaged $91 \pm 4 \%$ of $\mathrm{H}_{2}$ outputs $(P<0.05)$, suggesting a small but systematic error due to undetected recirculation of dye. The $\mathrm{H}_{2}$ technique appears ad-

This study was presented in part at the 42nd Scientific Session of the American Heart Association, Dallas, Tex. 1969.

Received for publication 21 December 1970 and in revised form 23 February 1971. vantageous for rapidly repeated determinations of output, for quantitation of small changes in output, and for situations in which recirculation of conventional indicators is a potentially significant problem.

\section{INTRODUCTION}

Conventional indicator-dilution techniques for measuring cardiac output are not optimum in patients with heart disease from at least three points of view: $(a)$ the validity of empirical corrections required to exclude recirculating indicator is uncertain when output is low and/or valvular regurgitation is present; $(b)$ even with repeated measurements, coefficients of variation (SD/ Mean $\times 100$ ) often exceed $\pm 10 \%$ and alterations in output of less than $\pm 20 \%$ are difficult to appreciate; (c) practical limitations make it difficult to repeat measurements more frequently than at 1-2 min intervals. In 1958, Chidsey, Fritts, Hardewig, Richards, and Cournand (1) suggested that the problem of recirculation could be minimized by employing constant-rate infusion of ${ }^{85} \mathrm{Kr}$, an inert gas which is $90-95 \%$ eliminated in a single passage through the lungs. These studies were extended by Rochester, Durand, Parker, Fritts, and Harvey from the same laboratory (2) and illustrative measurements were presented at $1 \mathrm{~min}$ intervāls during exercise. Certain disadvantages of the ${ }^{80} \mathrm{Kr}$ technique were identified: $(a)$ all expired air had to be collected during, and for several minutes after the completion of each measurement to avoid contamination of the test area with radioisotope; $(b)$ intrapulmonary elimination of ${ }^{85} \mathrm{Kr}$ was expected to be reduced in patients with ventilation-perfusion abnormalities; $(c)$ recirculation was still sufficiently large to require its measurement, thereby necessitating an additional sampling site and increasing the amount of blood withdrawn for each determination to $10 \mathrm{ml}$. More recently, studies in our laboratory have validated the use of dissolved hy- 
drogen $\left(\mathrm{H}_{2}\right)$ for the constant-rate injection technique (3). Since $\mathrm{H}_{2}$ is not radioactive and only trace amounts are employed, collection of expired air is unnecessary. Because $\mathrm{H}_{2}$ is only one-fourth as soluble as krypton, its intrapulmonary elimination is $97-99 \%$ complete in normal situations and it is theoretically less susceptible to ventilation-perfusion abnormalities (4). Measurement of recirculation is therefore also unnecessary. As little as $2 \mathrm{ml}$ of blood can be utilized for each measurement and it is practical to repeat measurements at 15sec intervals. The original studies validating the $\mathrm{H}_{2}$ technique were performed in experimental animals and showed agreement between the $\mathrm{H}_{2}$ and conventional Fick and dye dilution techniques, and between the $\mathrm{H}_{2}$ and a direct volumetric technique. The present study was intended to establish the utility of the $\mathrm{H}_{2}$ technique in conscious man; to explore its potentially unique advantages for rapidly repeated determinations and for quantitation of small changes in output; and to obtain comparative measurements between the $\mathrm{H}_{2}$, Fick, and dye dilution techniques, including one situation in which early recirculation is a potential problem, i.e., valvular regurgitation.

\section{METHODS}

Basic approach. The constant-rate injection $\mathrm{H}_{2}$ technique has been described in detail previously (3). $5 \%$ dextrose-in-water $(D / W)^{1}$ containing dissolved $\mathrm{H}_{2}$ is infused at a constant-rate upstream to the heart and intravascular $\mathrm{H}_{2}$ concentration is sampled downstream to the heart after complete mixing of incoming indicator and circulating blood. For right heart output, injection is into the systemic venous system and sampling from the pulmonary artery. For left heart output, injection is into the left atrium (or ventricle) and sampling from a systemic artery. Using the conventional formula :

Cardiac Output (ml/min)

where:

$$
=\frac{\text { Rate of infusion }(\mathrm{ml} / \mathrm{min}) \times \mathrm{CH}_{2 \text { Inf. }} .}{\left(\mathrm{CH}_{2 \text { Samp. site }}-\mathrm{C}_{\mathrm{H}_{\text {2ecirc. }} .}\right)}
$$

$$
\begin{gathered}
\mathrm{CH}_{2 \text { Inf. }}=\text { concentration of } \mathrm{H}_{2} \text { in infusate } \\
\mathrm{CH}_{2 \text { Samp. site }}=\text { concentration of } \mathrm{H}_{2} \text { in blood at the sampling } \\
\text { site } \\
\mathrm{CH}_{2 \text { Recire. }}=\begin{array}{c}
\text { concentration of } \mathrm{H}_{2} \text { in blood at a point just } \\
\text { proximal to the infusion site }
\end{array}
\end{gathered}
$$

All $\mathrm{H}_{2}$ concentrations are expressed in arbitrary chromatographic units per milliliter. In view of data presented below

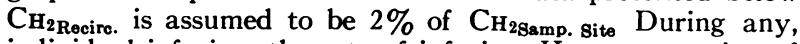
individual infusion, the rate of infusion, $\mathrm{H}_{2}$ concentration of the infusate and the small correction for incomplete $\mathrm{H}_{2}$ elimination remain constant. Repeated measurements of output may therefore be obtained as rapidly as downstream blood samples are drawn.

$H_{3}$ preparation, sampling, and analysis. $\mathrm{H}_{2}$ was passed from a standard gas cylinder through a sterile disposable

\footnotetext{
${ }^{1}$ Abbreviations used in this paper: $\mathrm{D} / \mathrm{W}$, dextrose-inwater.
}

filter ${ }^{2}$ and bubbled through an inverted infusion bottle of $5 \% \mathrm{D} / \mathrm{W}$ for $15-20$ min. $^{8}$ The $\mathrm{H}_{2} \mathrm{D} / \mathrm{W}$ was then poured into a sterile $200 \mathrm{ml}$ syringe ${ }^{4}$ and any air was carefully expelled. Infusion was accomplished with a gear-driven pump ${ }^{5}$ which was shown to be accurate within $\pm 1 \%$ of its calibration in preliminary experiments. Rates of infusion were usually 12 or $18 \mathrm{ml} / \mathrm{min}$. The large infusion syringe allowed for repeated determinations over a prolonged period. Blood samples were collected in heparinized $2.0 \mathrm{ml}$ glass syringes with male-Luer tips ${ }^{6}$ and sealed with mercury-filled metal caps." A "blank" blood sample was obtained before each $\mathrm{H}_{2}$ infusion, since small amounts of $\mathrm{H}_{2}$ are sometimes present in mixed venous blood (5). Sampling during $\mathrm{H}_{2}$ infusion was arbitrarily begun at $45-60 \mathrm{sec}$. In most patients, three to six samples were obtained during a 1-2 min period (individual samples being drawn over 10-20 sec). In some patients, sampling was less frequent but more prolonged.

The gas chromatographic system for measuring blood $\mathrm{H}_{\text {: }}$ concentration has been refined since its original description (6). The significant changes are illustrated in Fig. 1. Dissolved gases in each blood sample are "vacuum-extracted" for 2-3 min in a volumetric Van Slyke apparatus. Caprylic alcohol is used to minimize foaming but hemolyzing agents are unnecessary. The extracted gases are transferred to a $0.5 \mathrm{ml}$ sampling loop attached to what is normally the waste outlet of the Van Slyke apparatus. A switching valve allows the extracted gases to be inserted into the chromatographic-carrier gas stream. The chromatograph is a thermal conductivity unit housed in a constant-temperature water bath to achieve an improved signal-to-noise ratio. Water vapor and $\mathrm{CO}_{2}$ are removed from the extracted gases by adsorbents located between the sampling loop and the water bath. Since $\mathrm{O}_{2}$ is employed as the carrier gas, the large amount of $\mathrm{O}_{2}$ extracted from each blood sample is not detected. $\mathrm{H}_{2}$ is separated from the remaining gases (chiefly nitrogen and argon) by packed columns and detected with a sealed thermistor detector. $\mathrm{H}_{2}$ concentration is quantitated from the height of the $\mathrm{H}_{2}$ chromatographic peak and expressed as arbitrary chromatographic units per milliliters of blood. $\mathrm{H}_{2}$ concentration of the injectate is also measured chromatographically, using a $2.0 \mathrm{ml}$ portion sampled anaerobically from the infusion syringe. Previous studies (3) have shown that the peak height response of the chromatograph is linear within $1-3 \%$ over the range of $\mathrm{H}_{2}$ concentrations encountered and that the chromatograph has the same sensitivity for $\mathrm{H}_{2}$ in $\mathrm{D} / \mathrm{W}$ as for $\mathrm{H}_{2}$ in blood.

Quantitation of intrapulmonary $H_{3}$ elimination. 14 patients were studied in conjunction with routine cardiac catheterization. Pulmonary arterial- and systemic arterialblood samples were obtained for $\mathrm{H}_{2}$ analysis between 2 and $5 \mathrm{~min}$ of a constant-rate infusion of $\mathrm{H}_{2} \mathrm{D} / \mathrm{W}$ into the systemic venous system. $\mathrm{H}_{2}$ elimination was calculated by expressing the difference between pulmonary and systemic arterial $\mathrm{H}_{2}$ concentrations as a percentage of the pulmonary arterial concentration.

Output measurements. 42 patients were studied during routine cardiac catheterization. Right and left heart $\mathrm{H}_{2}$ measurements were employed interchangeably, the only cri-

\footnotetext{
${ }^{2}$ No. SXHA-013-0S, Millipore Corp., Bedford, Mass.

${ }^{3}$ When necessary, storage of compressed $\mathrm{H}_{2}$ can be avoided by use of a portable $\mathrm{H}_{2}$ generator ("Elhygen" $\mathrm{H}_{2}$ generator, Milton Roy Co., St. Petersburg, Fla.).

R-200-YL, Becton-Dickinson \& Co., Rutherford, N. J.

${ }^{5}$ Model 2202, Harvard Apparatus Co., Inc., Millis, Mass.

- Model 2YP, Becton-Dickinson \& Co.

${ }^{7}$ Model 425-A, Becton-Dickinson \& Co.
} 


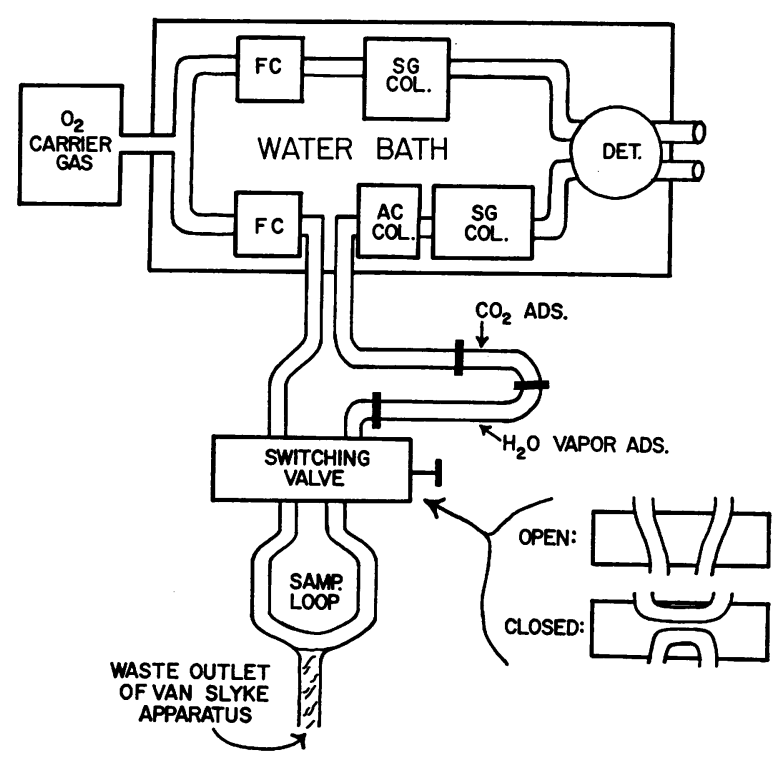

FIGURE 1 Schematic drawing of chromatographic system for $\mathrm{H}_{2}$ analysis. See text for details. FC, flow controller (Model 8843 ELF, Needle Taper 1, Brooks Instrument Co., Hatfield, $\mathrm{Pa}$.) ; the upper controller is set to deliver between 2 and $3 \mathrm{ml} / \mathrm{min}$ and the lower between 4 and $5 \mathrm{ml} /$ min. AC Col. $=3 \mathrm{ft}$. column, $\frac{1}{8}$ in. O.D., packed with activated charcoal. SG Col. $=7 \mathrm{ft}$. column, $\frac{1}{8}$ in. O.D., packed with silica gel. Det., thermal conductivity detector (Model 1160, Carle Instruments Inc., Fullerton, Calif.); this is operated at 11 MA. $\mathrm{CO}_{2}$ Ads., $\mathrm{CO}_{2}$ adsorbent (Ascarite, Arthur H. Thomas Co., Philadelphia, $\mathrm{Pa}$.), packed in $\frac{1}{8}$ in. O.D. tubing. $\mathrm{H}_{2} \mathrm{O}$ Vapor Ads., water vapor adsorbent (4A molecular sieve), also packed in $\frac{1}{8}$ in. O.D. tubing. Switching Valve, model L-206-4, Loenco, Inc., Altadena, Calif. Samp. Loop, sampling loop; this is fused to the waste outlet of the Van Slyke apparatus; the fluid level is adjusted as shown before the switching valve is opened.

terion being the location in which catheters were already in place. Eight additional patients were studied during treatment for acute complications of arteriosclerotic heart disease in a Coronary Care Unit. Right heart measurements were employed in all cases, using a Swan-Ganz flow-directed catheter $^{8}$ to obtain pulmonary-arterial blood samples (7).

14 of the patients undergoing routine catheterization also had nearly simultaneous measurements of cardiac output by the direct Fick method. $\mathrm{O}_{2}$ uptake was obtained using either closed-circuit rebreathing of pure $\mathrm{O}_{2}$ (with absorption of $\mathrm{CO}_{2}$ ) or collection and analysis of expired air. When using expired air collection, pulmonary and systemic-arterial blood samples were obtained at the midpoint of each determination and analyzed for $\mathrm{O}_{2}$ content with a manometric Van Slyke apparatus. When closed-circuit rebreathing was employed, blood samples were taken just before the rebreathing was begun.

24 patients undergoing routine catheterization also had measurements of cardiac output by dye dilution techniques. For each curve, a $3.0 \mathrm{ml}$ bolus containing $3.75 \mathrm{mg}$ of indo-

\footnotetext{
${ }^{8}$ Model 93-110-5F, Edwards Laboratories, Santa Anna, Calif.
}

cyanine green dye ${ }^{\bullet}$ was injected through an atrial catheter and flushed rapidly with 6-9 $\mathrm{ml}$ of isotonic saline. Arterial blood was sampled with a Gilford Model 103-IR cuvette densitometer ${ }^{10}$ using rates of withdrawal of 23 or $46 \mathrm{ml} /$ min. The densitometer was calibrated using the patient's own blood by the method outlined by Sinclair, Sutterer, Fox, and Wood (8). Each calibration curve included a minimum of two points in addition to zero. Since the calibration became alinear at the higher dye concentrations achieved, recorded curves were replotted in terms of actual dye concentrations before semilogarithmic extrapolation. The area was then obtained in the conventional fashion. Finally, each of the 24 patients was classified as having negligible or moderate-to-severe regurgitation on the basis of left ventricular cineangiograms interpreted independently by three observers.

\section{RESULTS}

Quantitation of intrapulmonary $\mathrm{H}_{2}$ elimination. $\mathrm{H}_{2}$ elimination averaged $98 \pm 1.5 \%$ (SD) and was in no case less than $96 \%$. Mean left atrial pressures ranged from 13 to $28 \mathrm{~mm} \mathrm{Hg}$ and averaged $19 \pm 7 \mathrm{~mm} \mathrm{Hg}$, but there was no statistical correlation between $\mathrm{H}_{2}$ elimination and left atrial pressure. On the basis of these and similar data in anesthetized animals (3), we have elected to assume a constant elimination of $98 \%$ in all subsequent studies.

Output measurements. Reproducibility of output measurements was evaluated using triplicate $\mathrm{H}_{2}$ determinations obtained over $45-60 \mathrm{sec}$ in 25 consecutive patients. Average values of output in individual patients ranged from 2.21 to 8.63 liters $/ \mathrm{min}$ and averaged 4.18 liters $/ \mathrm{min}$.

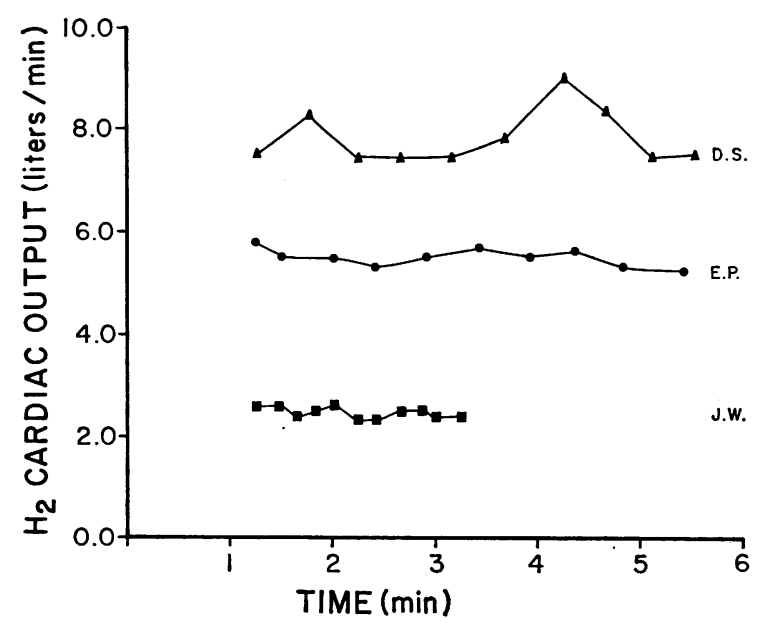

FIgURE 2 Multiple sequential measurements in three patients. Mean cardiac outputs were $7.81 \pm 0.52$ (SD) liters/ $\min$ (D. S.), $5.45 \pm 0.24$ liters/min (E.P.) and $2.47 \pm 0.10$ liters/min (J. W.). In patient J. W., $\mathrm{H}_{2}$ samples were drawn as rapidly as possible.

\footnotetext{
' Cardiogreen, Hynson, Westcott \& Dunning, Inc., Baltimore, $\mathrm{Md}$.

${ }^{10}$ Gilford Instrument Labs, Oberlin, Ohio.
} 
Coefficients of variation $(\mathrm{sD} /$ mean $\times 100)$ for triplicate determinations ranged from 1.0 to $7.5 \%$ and averaged $3.4 \pm 2.0 \%$ (SD). Fig. 2 illustrates a similar reproducibility for multiple sequential determinations over somewhat longer periods of time.

Fig. 3 illustrates the use of $\mathrm{H}_{2}$ measurements to evaluate relatively small changes in output at different pacing rates in Coronary Care Unit patients with complete heart block. In patient D. J., a spontaneous heart rate of 64 was accompanied by a cardiac output of 2.27 \pm 0.03 (SEM) liters min. Ventricular pacing at rates of 80 and 96 increased output to $2.58 \pm 0.04$ liters $/ \mathrm{min}$ $(P<0.01)$ and $2.81 \pm 0.04$ liters $/ \mathrm{min} \quad(P<0.01)$. An additional increase in rate to 120 was associated with an output of $2.99 \pm 0.06$ liters $/ \mathrm{min}$ but this value did not differ significantly from that at a rate of 96 . In patient M. B., a cardiac output of $2.18 \pm 0.06$ liters $/ \mathrm{min}$ at a spontaneous rate of 56 did not differ significantly from outputs of $2.32 \pm 0.02$ and $2.36 \pm 0.06$ at ventricular pacing rates of 80 and 102 .

Fig. 4 illustrates the use of repeated $\mathrm{H}_{2}$ measurements to follow trends in cardiac output during the early stages of acute myocardial infarction. In patient W. O., cardiac index was at the upper limits of normal on admission $\left(3.62 \pm 0.08\right.$ liters $/ \mathrm{min}$ per $\left.\mathrm{m}^{2}\right)$. During the first $24 \mathrm{hr}$ in the Coronary Care Unit, it dropped to $2.38 \pm 0.04$ liters/min per $\mathrm{m}^{2}$ and then returned to a clearly normal value. Pulmonary arterial pressures was elevated during the first $24 \mathrm{hr}$ but then returned to within normal limits. In contrast, patient $\mathrm{H}$. C. exhibited a cardiac index which was consistently in the normal range.

Fig. 5 illustrates comparative $\mathrm{H}_{2}$ and direct Fick measurements during cardiac catheterization. When each $\mathrm{H}_{2}$ measurement was expressed as a percentage of the

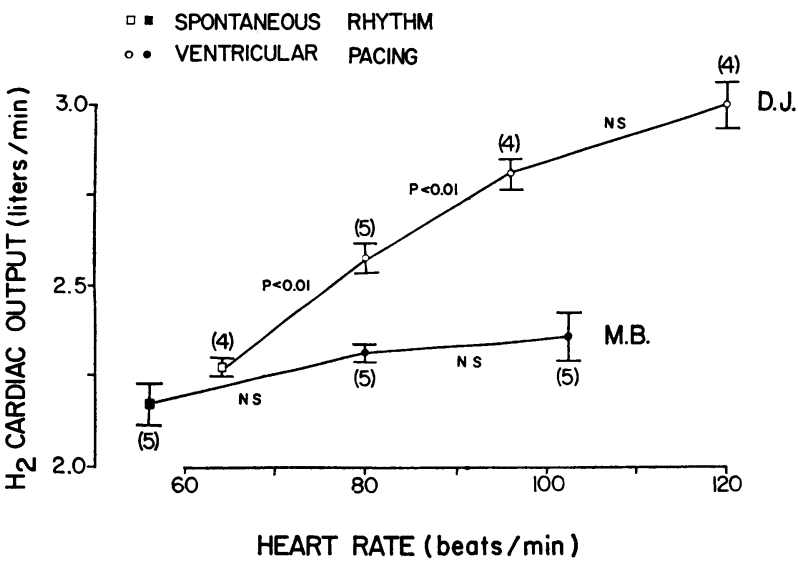

FIgURE 3 Use of groups of $\mathrm{H}_{2}$ outputs to determine effects of different pacing rates in two patients with complete heart block. Numbers in parentheses, number of $\mathrm{H}_{2}$ determinations used to calculate each mean value. Vertical bars represent \pm 1 SEM.
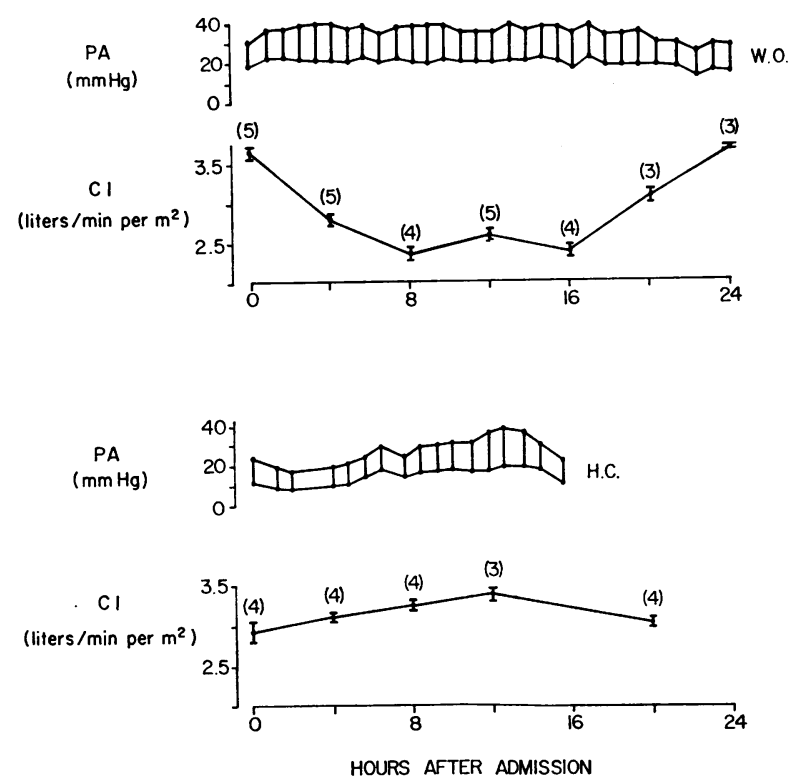

FIgURE 4 Use of $\mathrm{H}_{2}$ cardiac indices for following trends in acute myocardial infarction. Abbreviations, etc. as in Fig. 3. CI, cardiac index.

corresponding Fick measurement, $\mathrm{H}_{2}$ outputs averaged $106 \pm 4 \%$ (SEM) of Fick outputs ( $P>0.1$, paired " $t$ " test using absolute values for cardiac index). The correlation coefficient was $0.86(P<0.01)$.

Fig. 6 illustrates comparative $\mathrm{H}_{2}$ and dye measurements during cardiac catheterization. Both dye and $\mathrm{H}_{2}$ were injected into the left atrium and sampled from a systemic artery. There was no significant difference between dye and $\mathrm{H}_{2}$ outputs when the group was considered as a whole $(P>0.1$, paired " $t$ ") or when comparisons were confined to patients with indices $<2.5$ liters/min per $\mathrm{m}^{2}(P>0.1$ regardless of whether dye or $\mathrm{H}_{2}$ is used as a reference). When the total group was divided into patients with and without valvular regurgitation, results differed. In patients without regurgitation, dye indices ranged from 91 to $118 \%$ and averaged $106 \pm 3 \%$ (SEM) of $\mathrm{H}_{2}$ indices $(P>0.1)$. In patients with regurgitation, dye indices ranged from 61 to $114 \%$ and averaged $91 \pm 4 \%$ of $\mathrm{H}_{2}$ indices $(P<0.05) .10$ of the regurgitation patients were also studied with rightatrial dye injection and arterial sampling, and rightatrial dye indices ranged from 58 to $106 \%$ and averaged $88 \pm 4 \%$ of $\mathrm{H}_{2}$ indices $(P<0.05)$.

\section{DISCUSSION}

The most obvious advantage of using dissolved $\mathrm{H}_{2}$ as an indicator for measuring cardiac output is the absence of recirculation. General principles governing the intrapulmonary elimination of a dissolved gas infused intravenously have been summarized by Farhi and his col- 


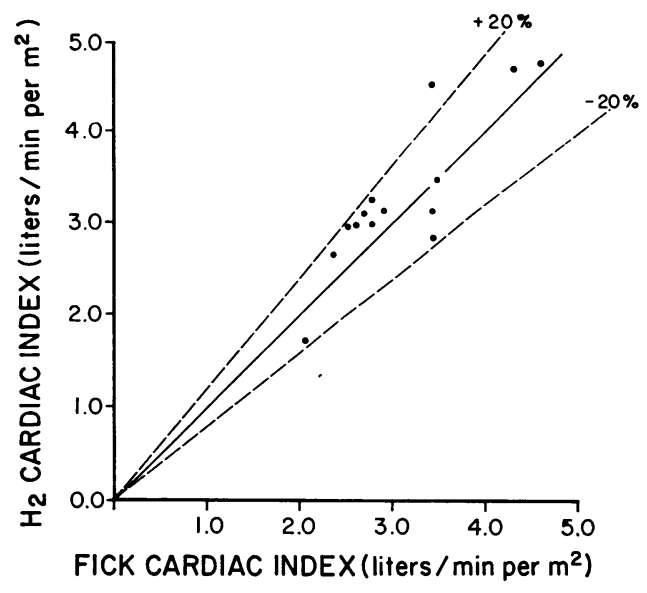

FIGURE 5 Comparison of measurements of cardiac index by constant-rate $\mathrm{H}_{2}$ injection and direct Fick methods.

leagues $(4,9)$. The crucial steady-state parameters are the solubility of the gas and the ventilation-perfusion ratio of each alveolus. Gas elimination is directly related to ventilation-perfusion ratio and inversely related to solubility, and can be approached from two viewpoints: (a) any intrapulmonary shunt in which mixed venous blood is not exposed to alveolar air will be totally ineffective for elimination of $\mathrm{H}_{2}$ (and all other gases); (b) since the amount of true intrapulmonary shunting is, at least in normal situations, only $0.2 \%(10)$, the alveoli of crucial importance are those with ventilationperfusion ratios which are abnormally low but greater than zero. These alveoli are notoriously ineffective for $\mathrm{O}_{2}$ and $\mathrm{CO}_{2}$ exchange $(4,9)$ and, from that viewpoint, are "effective shunts." On the other hand, they remain surprisingly effective for $\mathrm{H}_{2}$ elimination. For example, an alveolus with a ventilation-perfusion ratio of 0.2 may raise mixed venous $\mathrm{O}_{2}$ content by only half the amount required to achieve full saturation but still eliminate $93 \%$ of incoming $\mathrm{H}_{2}$. An alveolus with a "normal" ventilation-perfusion ratio of 0.8 is only $5 \%$ more effective in eliminating incoming $\mathrm{H}_{2}$. In the present studies, the relatively brief durations of $\mathrm{H}_{2}$ infusion probably had the additional advantage of being too short to allow systemic arterial $\mathrm{H}_{2}$ concentrations to rise to true steady-state levels. Because of $\mathrm{H}_{2}$ 's extremely low solubility $(\alpha=0.015 \mathrm{ml} / \mathrm{ml}$ per $760 \mathrm{~mm} \mathrm{Hg})$, even a nonventilated alveolus can remove significant amounts of $\mathrm{H}_{2}$ from mixed venous blood during the first few minutes of an $\mathrm{H}_{2}$ infusion.

In any event, the measured values for $\mathrm{H}_{2}$ elimination in the patients in this study do not differ from those previously reported for normal experimental animals (3), despite significant elevations in left atrial pressure. On the basis of these values we have made it a practice to multiply downstream $\mathrm{H}_{2}$ concentration by 0.98 to correct for the small amount of $\mathrm{H}_{2}$ not normally eliminated from mixed venous blood. This correction is admittedly arbitrary. Since it represents an average value, it will not be precisely correct for all individuals. In addition, since it does not take into account $\mathrm{H}_{2}$ removal from arterial blood by body tissues during the first few minutes of an $\mathrm{H}_{2}$ infusion, it may overestimate the amount of recirculating $\mathrm{H}_{2}$ reaching the sampling site. In view of these considerations and the small size of the correction, some workers may prefer to omit it. It will continue to be important, however, to make direct measurements of $\mathrm{H}_{2}$ elimination when the $\mathrm{H}_{2}$ technique is applied to abnormal situations not previously studied.

The ease of obtaining multiple samples with the $\mathrm{H}_{2}$ technique seems noteworthy. As mentioned above, the standard deviation of three consecutive measurements during a steady-state is $3 \%$ of the mean value. When evaluating changes in flow with single sequential samples (e.g., Fig. 2), statistical significance can be ascribed to changes of less than $\pm 10 \%$. In addition, the ability to draw samples at 15-sec intervals (as opposed to 1-2 min intervals) means that changes of relatively short periodicity may be identified. Using sequential groups of $\mathrm{H}_{2}$ flows (e.g., Figs. 3 and 4), standard errors of mean values are sometimes as small as $2-3 \%$ and statistical significance may be associated with means differing by as little as $\pm 5 \%$. The studies in patients with acute complications of arteriosclerotic heart disease are of particular interest in this regard. Trends are easily identified even when absolute changes are small.

There is relatively little information available to make a similar evaluation for dye dilution measurements. Smulyan (11) has analyzed the variability of 67 duplicate indicator dilution studies culled from five laboratories and has stated that reproducibility (i.e., \pm 2 SD

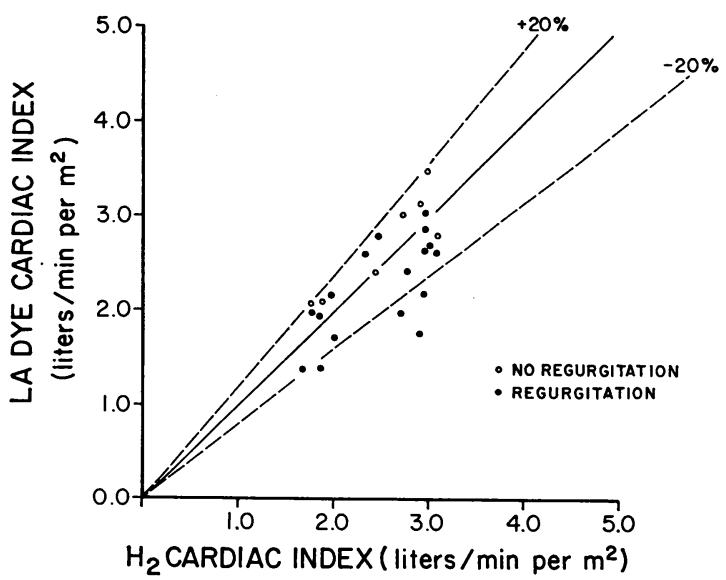

FIgURE 6 Comparison of measurements of cardiac index by constant-rate $\mathrm{H}_{2}$ injection and dye dilution. Each dye value represents the mean of two to four consecutive determinations. LA Dye, left atrial dye injection. 
of mean difference) is $\pm 24 \%$. In our laboratory, 31 paired dye measurements yielded a reproducibility of the same order of magnitude, i.e., $\pm 18 \%$. Using three dye curves, we were able to improve reproducibility to $\pm 12 \%$. It is possible that sets of more than three dye curves may be used with even smaller differences. We have found it more practical to obtain multiple $\mathrm{H}_{2}$ measurements during a short (1-2 $\min ) \mathrm{H}_{2}$ infusion. This also allows us to take advantage of the somewhat greater reproducibility of this technique.

The $\mathrm{H}_{2}$ technique is susceptible to the same sampling errors as other indicator-dilution techniques utilizing constant-rate injection (12). However, Bassingthwaighte, Knopp, and Anderson (13) have pointed out that errors related to time-averaged sampling may be significantly less during constant-rate injection than during bolus injection. Even disregarding the possibility of sampling errors, a change in cardiac output is not instantaneously reflected in a change in downstream $\mathrm{H}_{2}$ concentration because of the effects of the mixing chamber interposed between the sites of injection and sampling. Rochester and his colleagues (2) have analyzed the change from one steady-state indicator concentration to another assuming a monoexponential washout of indicator from the right heart. Their approach suggests that $90 \%$ of any change in downstream concentration should be achieved in less than $5 \mathrm{sec}$ in normal hearts and in less than $15 \mathrm{sec}$ in abnormally large hearts with a low stroke volume. Since indicator washout is probably not a monoexponential process, a more precise statement is that of Zierler and his colleagues (14), who have emphasized that downstream indicator concentration becomes a valid representation of an altered output only when the last particle of indicator which entered the circulation before the alteration has passed the sampling site. As far as the present technique is concerned, there is no possibility of obtaining beat-to-beat changes. It is also unlikely that the full magnitude of respiratoryinduced variations of output can be appreciated.

The present $\mathrm{H}_{2}$ and Fick measurements are felt to show reasonable agreement. Admittedly, ideal validation of a technique for measuring cardiac output requires comparison against an absolute standard. The constantrate injection $\mathrm{H}_{2}$ technique has been validated in this fashion in experimental animals, using volumetric measurements of cardiac output during right heart by-pass (3). Similar measurements have not been feasible in man.

The comparative $\mathrm{H}_{2}$ and dye measurements require consideration from several points of view. A particularly controversial area is the adequacy of the traditional exponential extrapolation in abnormal hemodynamic states. As Zierler has pointed out (14), any treatment of recirculation is likely to be satisfactory when recircu- lation occurs late in the course of the primary dilution curve. Uncertainty arises as recirculation begins earlier in the curve. Oriol, Sekelj, and McGregor have clearly demonstrated failure of the extrapolation to detect coronary recirculation in experimental and clinical shock $(15,16)$. Maseri, Caldini, Permutt, and Zierler (17) have also presented an analogue model indicating how undetected recirculation could cause an incorrectly slow exponential decay to be assumed. The present findings are compatible with a small but systematic error due to undetected recirculation of dye in valvular regurgitation. The magnitude of the error approaches that reported by Rahimtoola and Swan (18) but is somewhat greater than that reported by Samet, Bernstein, and Castillo (19). A more definitive interpretation of the present data is complicated by the many possible reasons other than recirculation for a discrepancy between dye dilution and another technique for measuring flow. Although these factors cannot be reviewed in the present paper, several of them have been summarized in the recent studies of Saunders, Hoffmann, Noble, and Domenech (20). Our over-all feeling is that the magnitude of potential errors related to undetected recirculation and these other factors has not been fully defined, particularly in abnormal states. In our own laboratory, $\mathrm{H}_{2}$ measurements are more easily performed than dye measurements and some of these "uncertainties" are avoided.

Two potential limitations of the constant-rate injection $\mathrm{H}_{2}$ technique should be mentioned specifically. Our usual practice is to infuse $\mathrm{H}_{2} \mathrm{D} / \mathrm{W}$ at rates of 12 or $18 \mathrm{ml} / \mathrm{min}$. Even though the infusate does not contain saline, the volume of fluid delivered must be maintained within acceptable limits. In order to decrease the amount of fluid administration, one may utilize larger downstream samples for $\mathrm{H}_{2}$ analysis-e.g., when $6 \mathrm{ml}$ samples are employed, the rate of infusion can be reduced by a factor of three. The technique also requires a sampling as well as an infusion site on the venous (or arterial) side of the lungs. The advent of the SwanGanz catheter has made pulmonary arterial sampling appreciably more practical in the acute care situation.

\section{ACKNOWLEDGMENTS}

The authors would like to gratefully acknowledge the assistance of Mrs. Gretchen Smith, Mrs. Vernette Patterson, Mrs. Velma Ferguson, Mr. Percy Wilson, Mrs. Ruth Murphy, Miss Dorothy Antkowick, and Miss Beth Sloan. In addition, the assistance of Dr. Robert C. Koberstein, Dr. David E. Pittman, and Dr. John P. Visco in the preliminary phases of these studies is gratefully acknowledged.

This investigation was supported by Contract 69-28 from the Myocardial Infarction Branch of the National Heart and Lung Institute; by Research Grant HE-09587 from the National Heart and Lung Institute; and by a Grant-in-Aid from the Heart Association of Western New York. 


\section{REFERENCES}

1 Chidsey, C. A., III, H. W. Fritts, Jr., A. Hardewig, D. W. Richards, and A. Cournand. 1959. Fate of radioactive krypton $\left(\mathrm{Kr}^{85}\right)$ introduced intravenously in man. J. Appl. Physiol. 14: 63.

2. Rochester, D. F., J. Durand, J. O. Parker, H. W. Fritts, Jr., and R. M. Harvey. 1961. Estimation of right ventricular output in man using radioactive krypton $\left(\mathrm{Kr}^{85}\right)$. J. Clin. Invest. 40: 643.

3. Klocke, F. J., D. G. Greene, and R. C. Koberstein. 1968. Indicator-dilution measurement of cardiac output with dissolved hydrogen. Circ. Res. 22 : 841.

4. Farhi, L. E., and T. Yokoyama. 1967. Effects of ventilation-perfusion inequality on elimination of inert gases. Resp. Physiol. 3: 12.

5. Levitt, M. D. 1969. Production and excretion of hydrogen gas in man. N. Engl. J. Med. 281: 122.

6. Klocke, F. J. 1967. Measurement of trace amounts of inert gases in blood by gas chromatography. In Lectures on Gas Chromatography, 1966, L. R. Mattick and H. A. Szymanski, editors. Plenum Publishing Corporation, New York. 75.

7. Swan, H. J. C., W. Ganz, J. Forrester, H. Marcus, G. Diamond, and D. Chonette. 1970. Catheterization of the heart in man with use of a flow-directed balloon-tipped catheter. N. Engl. J. Med. 283: 447.

8. Sinclair, J. D., W. F. Sutterer, I. J. Fox, and E. H. Wood. 1961. Apparent dye-dilution curves produced by injection of transparent solutions. J. Appl. Physiol. 16: 669.

9. Farhi, L. E. 1967. Elimination of inert gas by the lungs. Resp. Physiol. 3: 1 .

10. Mellemgaard, K., N. A. Lassen, and J. Georg. 1962. Right-to-left shunt in normal man determined by the use of tritium and krypton 85. J. Appl. Physiol. 17: 778.
11. Smulyan, H. 1961. Reliability of the indicator-dilution technique. Amer. Heart J. $62: 140$.

12. Cropp, G. J. A., and A. C. Burton. 1966. Theoretical considerations and model experiments on the validity of indicator dilution methods for measurements of variable flow. Circ. Res. 18: 26.

13. Bassingthwaighte, J. B., T. K. Knopp, and D. U. Anderson. 1970. Flow estimation by indicator dilution (bolus injection): Reduction of errors due to timeaveraged sampling during unsteady flow. Circ. Res. 27: 277.

14. Zierler, K. L. 1962. Circulation times and the theory of indicator-dilution methods for determining blood flow and volume. Handb. Physiol. 1: 585.

15. Oriol, A., P. Sekelj, and M. McGregor. 1967. Limitations of indicator-dilution methods in experimental shock. J. Appl. Physiol. 23: 605.

16. Oriol, A., and M. McGregor. 1967. Indicator-dilution methods in estimation of cardiac output in clinical shock. Amer. J. Cardiol. 20: 826.

17. Maseri, A., P. Caldini, S. Permutt, and K. L. Zierler. 1970. Frequency function of transit times through dog pulmonary circulation. Circ. Res. 26: 527.

18. Rahimtoola, S. H., and H. J. C. Swan. 1965. Calculation of cardiac output from indicator-dilution curves in the presence of mitral regurgitation. Circulation. 31: 711.

19. Samet, P., W. H. Bernstein, and C. Castillo. 1966. Validity of indicator-dilution determinations of cardiac output in patients with mitral regurgitation. Circulation. 33: 410.

20. Saunders, K. B., J. I. E. Hoffman, M. I. M. Noble, and R. J. Domenech. 1970. A source of error in measuring flow with indocyanine green. J. Appl. Physiol. 28: 190. 